\title{
Longevity of Survival of Trichodermaharzianumon Sucrose added Cakes
}

\author{
Adesh Kumar ${ }^{1}$, Ramji Singh ${ }^{2}$, Bikesh Yadav ${ }^{3}$, Vipul Kumar ${ }^{1}$ \\ VinitPratapSingh $^{1}$ andVikram Singh ${ }^{2}$ \\ ${ }^{1}$ Lovely professional University, Phagwara (Punjab)-144411, India \\ ${ }^{2}$ Department of plant pathology, S.V.P. University of Agri. and Tech., Meerut (U.P.)-250110, India \\ ${ }^{3}$ Technical Assistant, UP Govt., Uttar Pradesh, India
}

\begin{abstract}
Tree borne oilseeds (TBOs) namely Neem cake, Jatropha cake, Mahua cake and Karanja cake were evaluated for mass culturing of Trichodermaharzianum showed that Neem cake is the best substrate in vitro while Jatropha cake in vivo. The antagonist could be stored for more than 3 months but an increase in number of viable propagules up to 4 months was measured from all the substrates except Karanja (up to 105 days) when mixed with Sucrose; a kind of sugar. Among all substrates Neem cake found maintaining high population at 30 days of inoculation with T. harzianumin the form of colony forming units (CFUs) per gram of substrate.
\end{abstract}

Keywords:Tree born oilseeds (TBOs); sucrose; Trichodermaharzianum; self-life; longevity; viability etc.

\section{Introduction}

Since antagonists are present as low population in native soils, further augmentation of their density to reach a higher stability through artificial application is necessary. Various agricultural wastes and by-products for multiplication of bio-control agents have been used by several workers [1], [2], [3] and [4].

Trichodermaas an effective antagonist against a range of plant pathogens won considerable scientific attention [5] and [6]. Different organic media like Neem cake, coir pith, farmyard manure, and decomposed coffee pulp also have been suggested for its multiplication [7]. Therefore, a study was conducted to enhance the conidial yield of $T$. harzianum on these substrates using nutritional supplements.

\subsection{Sourcesandmaintenanceofculture}

\section{Materials And Methods}

\subsubsection{Collection of soil samples and isolation of bio-control agent}

To isolate the bio-control agent i.e., Trichodermaharzianum from rhizospheric soil, samples were collected from fields of Crop Research Centre (CRC) of university. For isolation, $1 \mathrm{~g}$ of soil sample was placed in a $250 \mathrm{ml}$ conical flask containing $100 \mathrm{ml}$ of sterilized distilled water (SDW) and mixed thoroughly. Different dilutions of working samples were prepared by diluting the stock solution. $1 \mathrm{ml}$ of last serial dilution i.e., $10^{-6}$ was spread on Trichoderma Selective Medium (TSM) for isolation of T. harzianum[8]. The plates were incubated for 7 days at $28 \pm 2^{\circ} \mathrm{C}$ and after incubation, pure culture was grown; it was initially hyaline but turned green as conidia produced [9].

\subsection{Maintenance of the culture}

The fungus was sub-cultured in the PDA slants and allowed to grow at $28 \pm 2^{\circ} \mathrm{C}$ temperature. The culture thus obtained was stored in refrigerator at $5^{0} \mathrm{C}$ for further study and was sub cultured periodically.

\subsection{Screeningofdifferentoilcakesformassmultiplicationof T. harzianum \\ 2.3.1 Collection of oil cakes and other substrates}

Cakes of Neem, Jatropha, Mahua and Karanja were collected from local agricultural productprocessing units and farms. Materials were cleaned and crushed (in heavy pestle \& mortar) to prepare a coarse powder (particles of approximately $1 \mathrm{~mm}$ diameter). Cakes were mixed with sterilized water (SDW) to maintain $25 \%$ moisture (10: $2.5, \mathrm{w} / \mathrm{v})$ and autoclaved at $1.1 \mathrm{~kg} / \mathrm{cm}^{2}$ for 20 minutes. The flasks were allowed to cool at room temperature prior to inoculation. Flasks containing substrates were inoculated with 3-4 days old actively growing culture of $T$. harzianum (2-3 bitsof about $5 \mathrm{~mm}$ size) under aseptic conditions in laminar flow. The flasks were shaken thoroughly once a day, and incubated at $28 \pm 2^{\circ} \mathrm{C}$ for 30 days. For each treatment, three replicates of flasks were maintained and arranged in a completely randomized manner (CRD). 


\subsection{Determination of population dynamics}

Population dynamics were determined by serial dilution plate technique. Growth and development of $T$. harzianum were monitored after each 15 days interval up to 120 days under laboratory conditions. 1g substrate of each cake was taken from each flask for colony forming units (CFUs) count, using PDA medium.

\subsection{Colony Forming Units (CFUs)}

\subsubsection{Serial dilution and CFUs counting}

One gram of sample (substrate where Trichoderma was being grown) was suspended in $10 \mathrm{ml}$ distilled water to make microbial suspension diluted 10 times, it will give 1: 10 conc. or $10^{-1}$ dilution of original sample, i.e. the original sample has been diluted to $1 / 10$ th. Similarly it was prepared up to $10^{-6}$ on dilution of the original sample. Finally $1 \mathrm{ml}$ of microbial suspension from last serial dilution i.e., $10^{-6}$ was added to sterile Petri dishes (triplicate in completely randomized manner) and incubated for 5 days at $28 \pm 2^{\circ} \mathrm{C}$. The density of cells, spores/conidia of T. harzianum can be measured in laboratory by Plate Dilution technique [10].

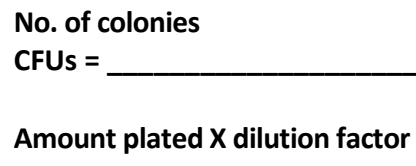

\subsection{Statistical analysis}

The data's were analyzed using ANOVA and treatment means differentiated using Fischer's completely randomized design (CRD) in vitro studies. Statistical analysis was conducted using general linear model procedures of SPSS version 16 [11] and [12].

\section{Results}

\subsection{Screeningofdifferentoilcakesadded with sucrose formassculturingof T. harzianum 3.1.1 AT 15 DAI}

Four oil cakes exhibited varying response toward sucrose, after 15 days of incubation. Neem cake (43.67 $\times 10^{6}$ CFUs) amended with sucrose emerged out to be significantly superior in giving rise to higher population dynamics followed by Jatropha cake $\left(40.67 \times 10^{6} \mathrm{CFUs}\right)$, Mahua cake $\left(37.00 \times 10^{6}\right)$. Karanja cake was found significantly lower than Mahua cake, which supported only $33.00 \times 10^{6}$ CFUs of $T$. harzianum(Table 2, Fig. 2).

\subsubsection{AT 30 DAI}

At 30 DAI, the highest mean population of the T. harzianum was supported by Neem cake $\left(67.67 \times 10^{6}\right.$ CFUs), which was significantly higher than the mean population supported by Jatropha cake $\left(57.00 \times 10^{6}\right)$. Mahua cake was next best formulation, which supported $51.67 \times 10^{6}$ CFUs of $T$. harzianum was significantly lower than Jatropha cake and followed by Karanja cake $\left(49.00 \times 10^{6}\right)$, which was found significantly lower to the Mahua cake (Table 2, Fig. 2).

\subsubsection{AT 45 DAI}

A slight reduction in CFUs was recorded after 45 days when Neem cake supported $60.67 \times 10^{6} \mathrm{CFUs}$ whereas, mean population supported by Jatropha cake is $50.00 \times 10^{6}$ followed by Mahua cake, which supported $44.67 \times 10^{6}$ CFUs, while lowest population was supported by Karanja cake i.e. $42.00 \times 10^{6}$ CFUs of $T$. harzianumand it was found significantly lower than Mahua cake (Table 2, Fig. 2).

\subsubsection{AT 60 DAI}

After 60 days, highest mean population of the T. harzianum was supported by Neem cake $\left(46.33 \times 10^{6}\right)$, which was significantly higher than Jatropha cake $\left(37.33 \times 10^{6}\right)$, Mahua cake $\left(32.00 \times 10^{6}\right.$ CFUs) and Karanja cake which supported $27.33 \times 10^{6}$ CFUs of $T$. harzianum. Karanja cake was found significantly lower than Mahua cake (Table 2, Fig. 2).

\subsubsection{AT 75 \& 90 DAI}

Neem cake found significant in supporting CFUs of T. harzianum, which supported $36.67 \times 10^{6}$ and was significantly higher than Jatropha cake, Mahua cake and Karanja cake which supported $27.00 \times 10^{6}, 22.67 \times 10^{6}$ and $18.67 \times 10^{6} \mathrm{CFUs}$, while after 90 days of inoculation maximum no. of CFUs were recorded again in Neem cake $\left(24.33 \times 10^{6}\right)$ followed by Jatropha cake $\left(21.67 \times 10^{6}\right)$, Mahua cake $\left(19.33 \times 10^{6}\right)$. Least performing cake was Karanja cake with $15.67 \times 10^{6}$ CFUs of T. harzianumand was found significantly lower than Mahua cake (Table 2, Fig. 2). 


\subsubsection{AT 105 \&120 DAI}

Even after 105 and 120 days of inoculation highest population dynamics of T. harzianum was exhibited by Neem cake $\left(20.00 \& 7.33 \times 10^{6}\right)$ found significantly higher than Jatropha cake $\left(15.33 \& 2.33 \times 10^{6}\right)$ while Mahua cake with supporting $12.67 \& 1.00 \times 10^{6} \mathrm{CFUs}$ and found significantly lower than Neem and Jatropha cake. Least population of $T$. harzianum was supported by Karanja cake $\left(10.33 \times 10^{6}\right)$ found significantly lower than others and didn't support any CFUs after 120 days (Table 2, Fig. 2).

\section{Discussion}

In order to find out an additional source of carbon which can support in enhancing the growth, sporulation and longevity of $T$. harzianum over a comparatively longer period, an experiment was conducted to test the efficacy of sucrose, as amended to four TBOs cakes i.e., Neem, Jatropha, Mahua and Karanja. It was interesting to note that addition of sucrose to these cakes resulted in increasing the survival of T. harzianum up to 120 days, whereas without addition survival was up to 105 days.

Thangavelu [13] reported that addition of jaggery $(10 \% \mathrm{w} / \mathrm{v})$ to the substrate i.e., dried banana leaves increased the multiplication of $T$. harzianum which survived up to more than 6 months on the stored substrate. The results obtained in present study in regards to CFUs enhancing effect of sucrose mixing to the de-oiled cakes are comparable with the previous work of Thangavelu [13] as jaggery is a raw form of sucrose which helped in enhancing the population of $T$. harzianum.

Bean and Wilcoxson [14] found the best growth of Helminthosporiumsativumand H. dictyoides on sucrose. Whereas, Chandwani and Munjal [15] reported that maltose was the best source of carbon followed by sucrose and lactose for $H$. sativum, $H$. oryzae, H. carbonumand $H$. gramineum that supports the finding of present investigation.

Microencapsulation with sugars, such as sucrose, molasses or glycerol, significantly $(P<0.05)$ increased the survival percentages of conidia after drying. Xixuan and Custis [16] suggested that microencapsulation of conidia with $2 \%$ sucrose solution resulted in the highest survival percentage of $T$. harzianum $\left(7.5 \times 10^{10}\right.$ CFUs) supports current findings of research performed. Result shown in present investigation found comparable with work of Sriramet al. [17] and they declared that the addition of glycerol at 3 and $6 \%$ extended the shelf-life (with viability of $>2 \times 10^{6} \mathrm{CFU} \mathrm{g}^{-1}$ ) for 7 and 12 months, respectively compared to 4-5 months shelf-life in formulations derived without the addition of glycerol.

Aamir et al. [18] also carried a study to assess the effects of temperatures $\left(20^{\circ} \mathrm{C}\right.$ or $\left.30^{\circ} \mathrm{C}\right)$ and sugars (dextrose or sucrose) on conidium germination and bioactivity as fresh conidia, or after 6 months of storage supported the findings of present study.

\section{Conclusion}

Neem cake was found to be superior among all the cakes at the entire DAIs followed by Jatropha cake. Mahua was next to the Jatropha in supporting the population of $T$. harzianum and the minimum CFUs were supported by Karanja cake up to 105 days after incubation without addition of Sucrose during the course of investigation (Table 1, Fig. 1). Once sucrose is added a positive effect in enhancing the CFUs and longevity of survival, has been noticed. Similarly without sucrose Jatropha and Mahua cakes couldn't support the $T$. harzianum population after 105 days, while with sucrose even these two cakes could support the population up to 120 days (Table 2, Fig. 2).

Sucrose is main constituent of several semi-synthetic or synthetic culture media for fungal isolation and further sub-culturing, thus, its role is well justified for fungal growth promotion. Sucrose being the disaccharide might have supplied comparatively little more amount of carbon than either mono-saccharides could have helped in increasing the longevity of T. harzianum in Jatropha and Mahua cakes from 105 to 120 days and also in increasing the population dynamics.

Table 1 Screening of different oil cakes up to 105 days after incubation (DAI) without added sugar

\begin{tabular}{|c|c|c|c|c|c|c|c|c|}
\hline \multirow[t]{2}{*}{ S.N. } & \multirow[t]{2}{*}{ Treatments } & \multicolumn{7}{|c|}{ CFUs x10 $^{6}$} \\
\hline & & 15 DAI & 30 DAI & 45 DAI & 60 DAI & 75 DAI & 90 DAI & 105 DAI \\
\hline $\mathbf{1}$ & Neem cake & $30.67^{\mathrm{a}}$ & $42^{a}$ & $30.33^{\mathrm{a}}$ & $22.67^{\mathrm{a}}$ & $17^{\mathrm{a}}$ & $10.33^{\mathrm{a}}$ & $0.67^{a^{*}}$ \\
\hline 2 & Jatropha cake & $27.33^{b^{*}}$ & $41.67^{b}$ & $26.33^{b}$ & $19.67^{b}$ & $16^{b}$ & $6.67^{b}$ & $0^{\mathrm{a}^{*}}$ \\
\hline 3 & Mahua cake & $26.67^{b *}$ & $39.33^{c}$ & $23.67^{c}$ & $15.67^{\mathrm{c}^{*}}$ & $14.33^{c^{*}}$ & $5.0^{c}$ & $0^{\mathrm{a}^{*}}$ \\
\hline 4 & Karanja cake & $24.67^{\mathrm{c}}$ & $36.33^{d}$ & $18.67^{d}$ & $15^{\mathrm{c}^{*}}$ & $13.67^{\mathrm{c}^{*}}$ & $2.33^{d}$ & $0^{a^{*}}$ \\
\hline
\end{tabular}

*Numbers followed by the same letter are not significantly different $(\mathrm{P}=0.05)$ 
Table 2Screening of different oil cakes up to 120 days after incubation (DAI) added with Sucrose

\begin{tabular}{|c|c|c|c|c|c|c|c|c|c|}
\hline \multirow[t]{2}{*}{ S.N. } & \multirow[t]{2}{*}{ Treatments } & \multicolumn{8}{|c|}{ CFUs x10 } \\
\hline & & $15 \mathrm{DAI}$ & 30 DAI & 45 DAI & 60 DAI & 75 DAI & 90 DAI & 105 DAI & 120 DAI \\
\hline 1. & Neem cake & $43.67^{a}$ & $67.67^{a}$ & $60.67^{a}$ & $46.33^{a}$ & $36.67^{a}$ & $24.33^{a}$ & $20.00^{a}$ & $7.33^{\mathrm{a}}$ \\
\hline 2. & Jatropha cake & $40.67^{b}$ & $57.00^{b}$ & $50.00^{b}$ & $\mathbf{3 7 . 3 3}^{\mathrm{b}}$ & $27.00^{b}$ & $21.67^{b}$ & $15.33^{b}$ & $2.33^{b}$ \\
\hline 3. & Mahua cake & $37.00^{c}$ & $51.67^{\mathrm{c}}$ & $44.67^{c}$ & $32.00^{c}$ & $22.67^{c}$ & $19.33^{c}$ & $12.67^{\mathrm{c}}$ & $1.00^{\mathrm{c}^{*}}$ \\
\hline 4. & Karanja cake & $33.00^{d}$ & $49.00^{d}$ & $42.00^{d}$ & $27.33^{d}$ & $18.67^{d}$ & $15.67^{d}$ & $10.33^{d}$ & $0.00^{c^{*}}$ \\
\hline
\end{tabular}

*Numbers followed by the same letter are not significantly different $(\mathrm{P}=0.05)$

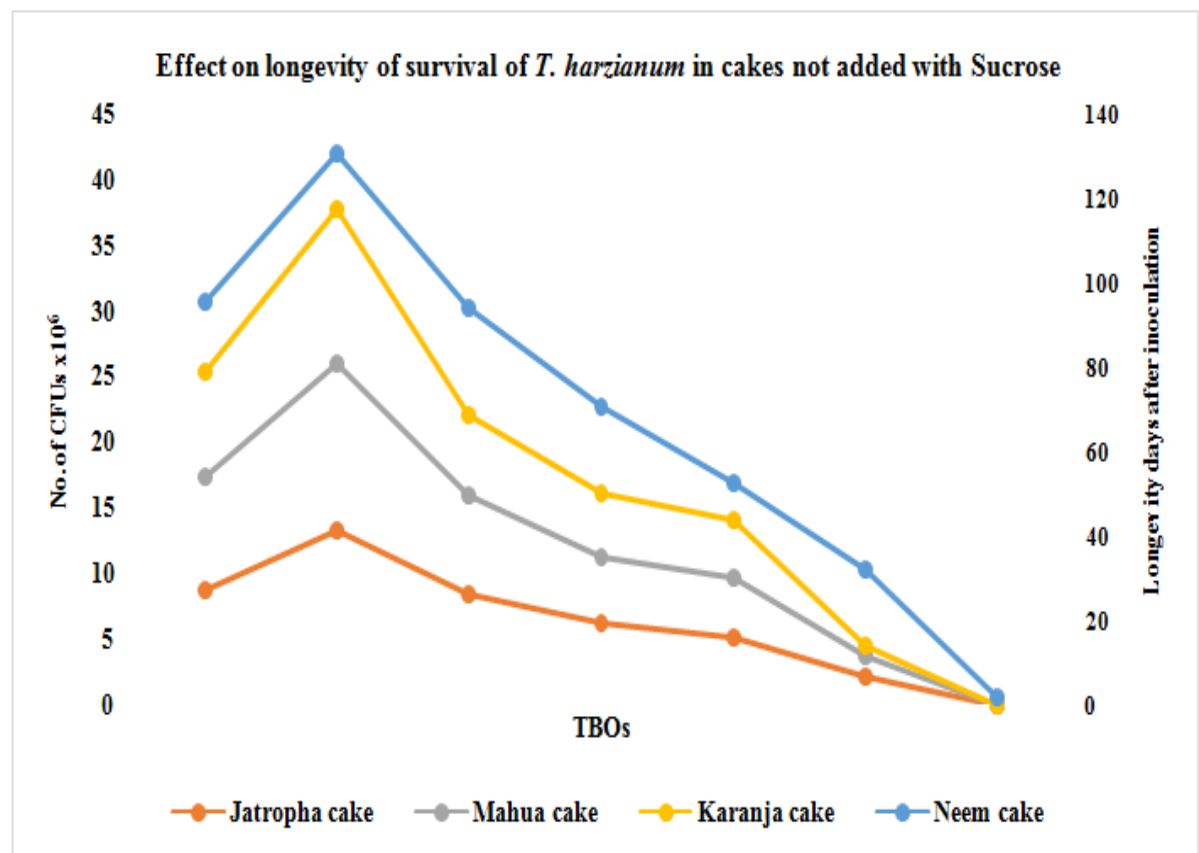

Fig. 1Screening up to 105 days of incubation into different TBOsnot added with Sucrose

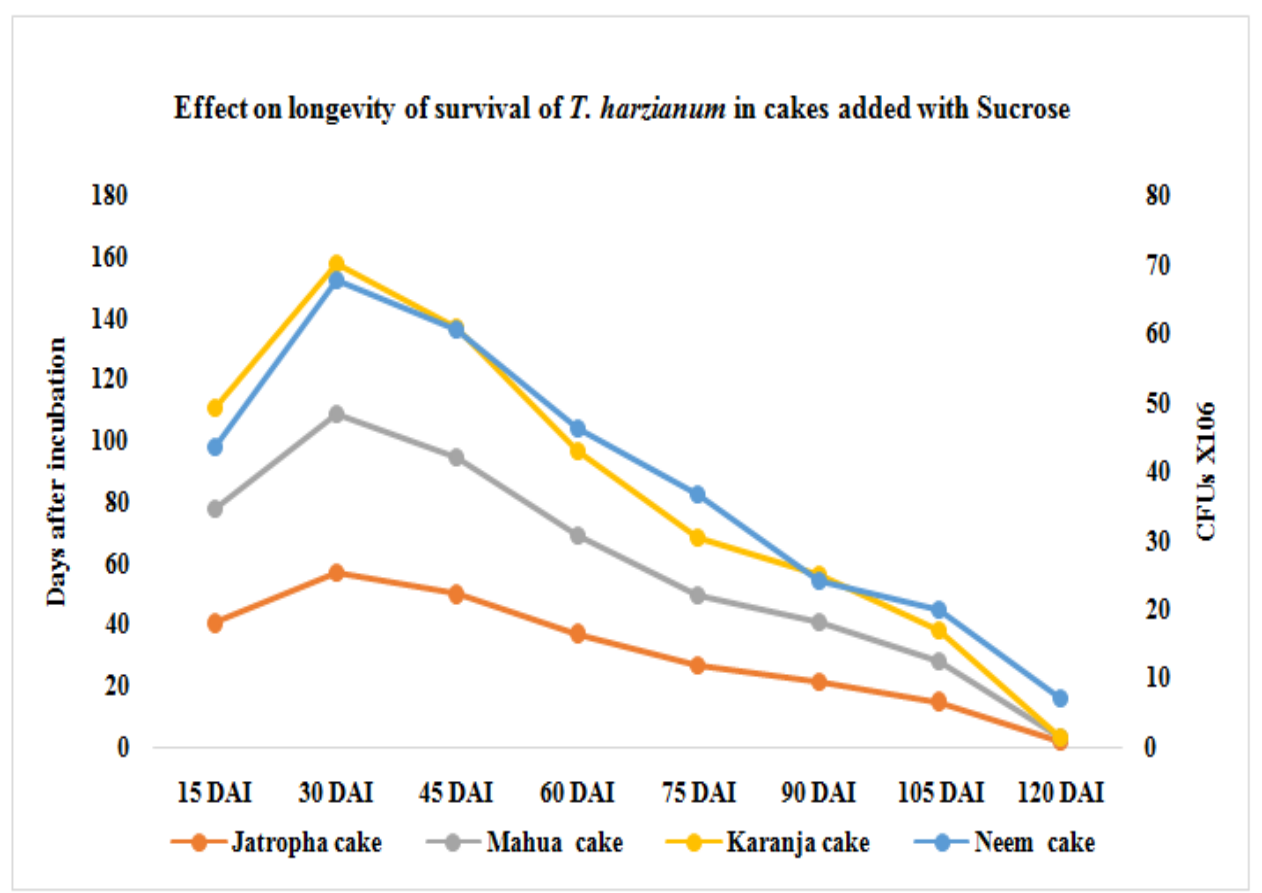

Fig. 2Screeningup to 120 days of incubation into different TBOs added with Sucrose

\section{Acknowledgement}


The facilities provided at SVPUA\&T, Meerut (Uttar Pradesh), India-250110 for the conduct of the study is thankfully acknowledged.

\section{References}

[1]. G. Kousalya and R. Jeyarajan, Mass multiplication of Trichoderma spp. Journal of Biological Control, 4, 1990, 408-414

[2]. I.S. Sawant and S. D. Sawant, Coffee fruit skin and cherry husk as substrates for mass multiplication of Trichoderma harzianum an antagonist of citrus Phytophthora, Indian Phytopathology,42, 1990, 336.

[3]. M. Anandaraj and Y. R. Sarma, Mature coconut water for mass culture of bio-control agents, Journal Plantation Crops, 25, 1997, $112-114$

[4]. A. Kumar, R. Singh, and A. Tomer, De-oiled cakes of Neem, Jatropha, Mahua and Karanja: A New Substrate for mass multiplication of T. harzianum, Journal of Plant Pathology \& Microbiology, 6 (7), 2015, 288-92.

[5]. A.K. Tewari and A.N. Mukhopadhyay, Testing of different formulations of Gliocladiumvirens against chickpea wilt complex, Indian Phytopathology, 54, 2001, 67-71.

[6]. C.R. Rini and K.K. Sulochana, Usefulness of Trichoderma and Pseudomonas against Rhizoctoniasolani and Fusariumoxysporum infecting tomato, Journal of Tropical Agriculture, 45 (1-2), 2007, 21-28.

[7]. Saju, K.A., Anandaraj, M., and Sarma, Y.R, On farm production of Trichodermaharzianum using organic matter, Indian Phytopathology, 55, 2002, 277-281.

[8]. Y. Elad and I. Chet, Improved selective media for isolation of Trichoderma and FusariumSpp, Phytoparasitica, 11,1983, 55-58.

[9]. M. Rifai, A revision of the genus Trichoderma, Mycological papers, 116, 1969, 1-56.

[10]. L.F. Johnson and E.A. Curl, Methods for Research on Ecology of Soil-borne Plant Pathogens (Burgers Publishing Co., Minneapolis, 1972).

[11]. A.K. Gomez and A.A. Gomez, Statistical Procedures for Agriculture Research (2 ${ }^{\text {nd }}$ Ed.) (John Willey and son's Press New York, 1996).

[12]. S.R.S. Chandel,A Hand book of Agricultural Statistics (10 ${ }^{\text {th }}$ ed.) (AchalPrakashanMandir, Kanpur, Uttar Pradesh, 2002)

[13]. R. Thangavelu, A. Palaniswami, and R. Velazhahan, Mass production of Trichodermaharzianumfor managing FusariumWilt of banana, Agriculture, Ecosystem \& Environment,103,2004, 259-263.

[14]. G.A. Bean and R.D. Wilcoxson,Helminthosporiumleaf spot of blue grass and pathogenicity of three isolates of Helminthosporiumin roots of blue grass, Phytopathology, 54, 1964, 1065-1070.

[15]. G.H. Chandwani and R.L. Munjal, Studies of physiology of HelminthosporiumgramineumRab.the causal agent of stripe disease of barley, Indian Phytopathology, 16, 1963, 301-306.

[16]. X. Jin and D. Custis, Micro-encapsulating aerial conidia of Trichodermaharzianum through spray drying at elevated temperatures, Biological Control, 56 (2), 2011, 202-208

[17]. S. Sriram, K.P. Roopa and M.J. Savitha, Extended shelf-life of liquid fermentation derived talc formulations of Trichodermaharzianum with the addition of glycerol in the production medium, Crop Protection, 30 (10), 2011, 1334-1339.

[18]. D. Amir, E.E. Jones, A. Hossein, R. G. Travis, and E. F. Richard, Biochemical characteristics of Trichodermaatroviride associated with conidium fitness for biological control, Bio-control Science and Technology, 26 (2), 2016, 189-205. 